\title{
Sex Differences in Energy Metabolism Need to Be Considered with Lifestyle Modifications in Humans
}

\author{
Betty N. Wu' ${ }^{1}$ and Anthony J. O'Sullivan ${ }^{1,2}$ \\ ${ }^{1}$ St. George Clinical School, Faculty of Medicine, University of New South Wales, Sydney, NSW 2052, Australia \\ ${ }^{2}$ Department of Medicine, St. George Hospital, Kogarah, NSW 2217, Australia
}

Correspondence should be addressed to Anthony J. O’Sullivan, a.osullivan@unsw.edu.au

Received 1 March 2011; Accepted 3 May 2011

Academic Editor: Andrea Buchholz

Copyright (C) 2011 B. N. Wu and A. J. O'Sullivan. This is an open access article distributed under the Creative Commons Attribution License, which permits unrestricted use, distribution, and reproduction in any medium, provided the original work is properly cited.

\begin{abstract}
Women have a higher proportion of body fat compared to men. However, women consume fewer kilojoules per kilogram lean mass and burn fat more preferentially during exercise compared with men. During gestation, women store even greater amounts of fat that cannot be solely attributed to increased energy intake. These observations suggest that the relationship between kilojoules consumed and kilojoules utilised is different in men and women. The reason for these sex differences in energy metabolism is not known; however, it may relate to sex steroids, differences in insulin resistance, or metabolic effects of other hormones such as leptin. When considering lifestyle modifications, sex differences in energy metabolism should be considered. Moreover, elucidating the regulatory role of hormones in energy homeostasis is important for understanding the pathogenesis of obesity and perhaps in the future may lead to ways to reduce body fat with less energy restriction.
\end{abstract}

\section{Introduction}

Fat gain is always considered to be a result of long-term positive energy balance, whereby daily energy intake exceeds expenditure. From the onset of puberty to menopause, women maintain a greater percentage body fat mass (FM) than men despite smaller energy intake per kg lean mass [1] and preferential use of fat as a fuel during exercise compared to men [2]. A potential reason for these findings is that the greater FM in women relates to more efficient fat storage during nonexercising periods, especially postprandial periods [3]. During pregnancy, women deposit between 2.4 to $5.9 \mathrm{~kg}$ of body fat, even when undernourished [4]. In well-nourished women, the energy cost of gestation is approximately $370 \mathrm{MJ}$ [5]. How this energy requirement is met is not explained purely by an increase in energy consumption, as past studies failed to demonstrate this in the first half of pregnancy $[6,7]$. The reproductive years and gestation are characterised by elevated levels of ovarian hormones. Evidence indicates that oestrogens contribute to the gender differences in FM and the gestational changes in body composition [3]. Human and animal studies have explored possible mechanisms of action by these hormones $[8,9]$. When considering lifestyle modifications, the sex difference in energy metabolism needs to be considered.

The first half of this paper focuses on differences between men and women: the gender differences in FM are outlined, aspects of energy metabolism that may account for these differences are discussed, and the key metabolic roles of ovarian hormones are discussed. Against this backdrop, the second half of this paper focuses on body composition and energy balance during pregnancy.

\section{Gender Differences in Body Composition Throughout Life}

Like many mammals, humans show significant differences in fat-free mass (FFM) and FM between the sexes. The National Health and Nutrition Examination Survey III (NHANES III) of 15,912 subjects, showed that non-Hispanic white females aged between 12 and 80 years have a higher percentage of FM than males, starting from puberty and varying from $6 \%$ to $11 \%$ higher for every decade studied (see Table 1 
Table 1: Percentage FM in healthy non-Hispanic white men and women. Adapted from NHANES III [10].

\begin{tabular}{lccc}
\hline Age range (years) & Males (\%) & Females (\%) & Difference (\%) \\
\hline $12-13.9$ & 18.4 & 24.8 & 6.4 \\
$20-29.9$ & 21.8 & 31.0 & 8.2 \\
$30-39.9$ & 23.6 & 33.0 & 9.4 \\
$40-49.9$ & 24.2 & 35.4 & 11.2 \\
$50-59.9$ & 25.1 & 37.3 & 12.2 \\
$60-69.9$ & 26.2 & 36.9 & 10.7 \\
$70-79.9$ & 25.1 & 35.9 & 10.8 \\
\hline
\end{tabular}

and Figure 1) [10]. Other studies also support the notion that the significant sexual divergence in body composition commences with puberty [3]. This sex difference holds across all ethnic groups and has been observed in all populations although its magnitude is influenced by ethnic, genetic, and environmental factors [11]. Not only is there a difference in percent FM between the sexes, there is also a well-recognised difference in body fat distribution.

\section{Gender Difference in Energy Metabolism}

It may be postulated that women store more fat because they consume more energy than they expend or that they store the consumed fat more efficiently. However, when daily energy intake is compared in the cohort of subjects from NHANES III, men consumed more energy, even after adjusting for fat-free mass $\left(187 \mathrm{kJkg}^{-1}\right.$ versus $\left.170 \mathrm{kJkg}^{-1}\right)$ $[1,10]$. One possible explanation is that women are more efficient at conserving energy and storing it as fat. Supporting this notion is the recognition that women must reduce their dietary intake by a greater proportion to achieve the same degree of weight loss as men [12]. Another observation is that in the first half of pregnancy, women increase their FM without evident increases in energy intake or decreases in expenditure. This ability to increase FM without substantial increases in energy intake points to the existence of metabolic adaptations that may contribute to the gender difference in FM.

3.1. Exercise Metabolism. Differences in rates of glucose and fat oxidation during exercise do not seem to explain the gender difference in FM. Women preferentially burn a higher fat-to-glucose fuel mixture during exercise [13]. Despite this, women lose less fat than men when faced with a similar energy deficit [14-17]. This may be related to more efficient fat storage during non-exercising periods $[18,19]$, considering less than $5 \%$ of the day is spent exercising in most healthy people. The higher fat mass in women may allow them to preferentially use this energy source as a fuel while exercising, whereas during the non-exercising times, women are storing fat more efficiently compared with men.

3.2. Postprandial Metabolism. Since women do not consume more energy compared to men, yet preferentially oxidise fat during exercise, it seems logical to propose that their higher

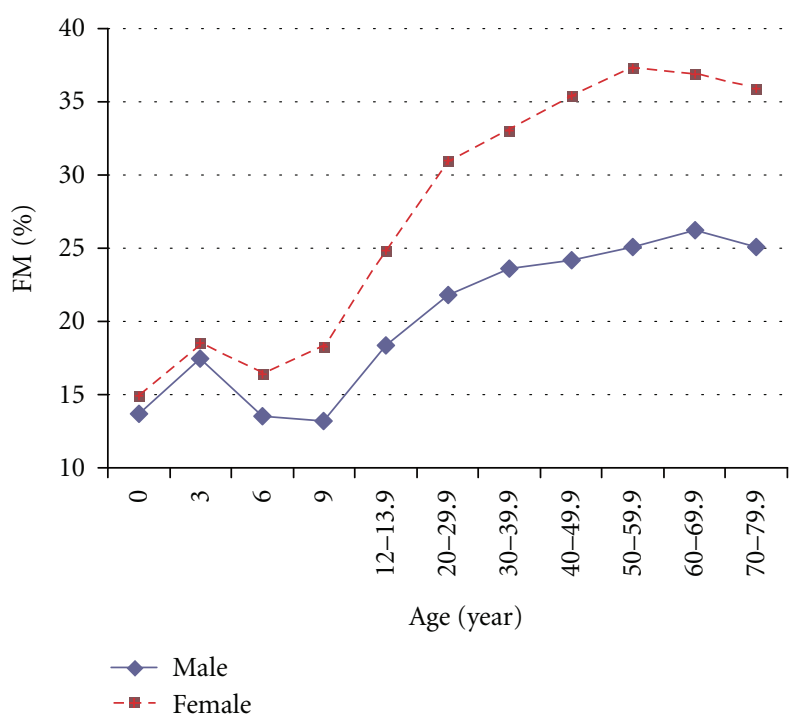

Figure 1: Percentage fat mass (FM) in males and females showing the divergence that occurs at puberty and persists through the premenopausal years. Combined data from Chumlea et al. [10] and Fomon et al. [20].

TABLE 2: Expression of sex hormone receptors in adipose tissues. Adapted from Mayes, 2004 [26].

\begin{tabular}{lcccc}
\hline \multirow{2}{*}{ Receptor } & \multicolumn{2}{c}{ Visceral fat } & \multicolumn{2}{c}{ Subcutaneous fat } \\
& Female & Male & Female & Male \\
\hline OR- $\alpha$ & + & + & ++ & + \\
OR- $\beta$ & + & + & +++ & +++ \\
PR-A & - & - & + & - \\
PR-B & + & - & ++ & - \\
AR & ++ & ++ & + & + \\
\hline
\end{tabular}

OR oestrogen receptor; PR progesterone receptor; $\mathrm{AR}$ androgen receptor.

FM is due to increased fat storage during non-exercising periods. Indeed, women were found to revert to a state of reduced fatty acid oxidation immediately after exercise, which persists for hours [21]. In addition, postprandial free fatty acid release from adipose tissue was reported to be lower in women than men $[22,23]$. Several cross-sectional studies comparing men and women demonstrated that men oxidised a greater percentages of ingested fat [24, 25]. Using radiotracers, these authors also showed that postprandial fatty acid uptake by upper body subcutaneous and lower body adipose tissues were higher in women than men. Since the amount of energy expended in postabsorptive and postprandial states is greater than during exercise, this will have a great bearing on overall fat storage and FM.

Oestrogen is believed to be partly responsible for this reduction in postprandial fatty acid oxidation. Prospective studies using oral oestrogen therapy reported reductions in postprandial fatty acid oxidation. One study found significant reductions in postprandial fatty acid oxidation associated with a small increase in FM [27]. Similar changes were found in growth-hormone-deficient women on oral 
oestrogen therapy [28]. Another study reported larger reductions in postprandial fatty acid oxidation with oral oestrogen compared with transdermal therapy associated with a significant increase in FM [29]. This route-dependent observation raises the possibility that oral oestrogen therapy exerts its influence on the liver during first-pass metabolism. Therefore, studies using exogenous oestrogens have demonstrated that efficient fat storage in women was mediated through reduced postprandial fatty acid oxidation most likely because of an oestrogenic influence on hepatic processing of dietary fats.

However, the metabolic effect of exogenous oestrogen treatment may differ from endogenous oestrogens for several reasons. Exogenous synthetic oestrogens are generally more potent [30], and they have different pharmacokinetic attributes [31]. Several types of endogenous oestrogens exist, and each may have slightly different or synergistic actions [30]. Prospective studies during the hyperoestrogenic state of pregnancy are ideal for investigating the effects of endogenous oestrogens on postprandial fatty acid oxidation. However, the logistical difficulties of studying pregnant women prepregnancy has meant that to date, there has been limited prospective studies, of sufficient sample size, on energy metabolism during pregnancy. Spaaij et al. [32] studied 27 women from pre-pregnancy to delivery. They found that postprandial fat oxidation did not differ from prepregnant values during the first 13 weeks and actually increased afterwards. In cross-sectional studies, Nagy and King [33] detected no difference in postprandial fatty acid oxidation between 6 nonpregnant and 10 pregnant subjects, while a larger study $(n=23)$ detected a significant reduction in fatty acid oxidation in the pregnant group [34]. However, due to significant intersubject variations, findings from cross-sectional studies should be interpreted with caution.

In conclusion, a reduction in postprandial fatty acid oxidation has been shown to promote FM gain. Exogenous oestrogen treatment appears to induce this reduction, possibly by suppressing hepatic processing of dietary fats during first-pass metabolism. However, due to the complex actions of endogenous oestrogens, the small number of studies, and inconsistencies in study design, the effects of endogenous oestrogens on metabolism requires further research.

\section{Regulation of Metabolism and Body Compo- sition by Sex Hormones}

Women's higher proportion of FM and the increase in FM during the first half of pregnancy may be due to the influence of sex hormones on metabolic processes such as lipolysis and fatty acid storage. In the literature reviewed, there is evidence to suggest that these effects can be mediated through hepatic targets, adipocyte targets, and adipokines such as leptin. However, how these pathways interplay is complex and generally poorly understood.

4.1. Hepatic Targets. Oestrogen may have an inhibitory effect on fatty acid oxidation on the liver, a major site on fatty acid metabolism. Several in vitro studies in murine hepatocytes showed that pharmacological concentrations of oestrogen reduced ketogenesis (a product of fatty acid oxidation) and increased fatty acid incorporation into triglycerides $[9,35]$. Similar findings were reported in human subjects, where oral oestrogen therapy administered to hypogonadal and postmenopausal women reduced postprandial fatty oxidation and increased triglyceride levels [29, 36-38]. This indicates that exogenous oestrogen directs intrahepatic fatty acids away from oxidative pathways and into lipogenic pathways.

In contrast, the effects of endogenous oestrogens are much harder to elucidate. Studies comparing women in follicular and luteal phases of the menstrual cycle detected no difference in energy metabolism, possibly because the change in oestrogen levels varies and there is also the influence of progesterone [24, 39]. Studies correlating oestrogen concentration and postprandial fatty acid oxidation in pregnant and non-pregnant subjects have looked at whole body metabolism of fat rather than isolating the effects on the liver. In addition, progesterone, which has been shown to have a synergistic and antagonistic effect, depending on the organ system, with oestrogen has not been studied in this context [8].

4.2. Adipocyte Targets. Oestrogen, progesterone and androgen receptors are present in adipose tissues [26]. As Table 2 shows, the expression of these receptors varies by depot and gender $[40,41]$. Oestrogen receptors are higher in subcutaneous deposits in women, which may explain why women have greater subcutaneous gluteal and femoral deposits of fat $[40,41]$. Genetic males with androgen insensitivity have a female body habitus [42], while women given exogenous androgens or suffering from virilising disorders will develop a male body habitus [40, 43-45]. Postmenopausal women experience an increase in waist to hip ratio and the amount of the visceral adipose tissue depot [32, 46, 47], which is partially reversed by oestrogen administration [48]. All this evidence indicates that the binding of sex hormones to their adipose tissue receptorspossibly promotes adipogenesis in some regions of the body. Although, it is known that many genes inadipocytes are transcriptionally regulated by sex hormones [26], the precise cellular mechanisms have not been fully elucidated.

4.3. Leptin. Leptin is an adipose tissue-derived hormone that inhibits fat gain by promoting hypophagia and hypermetabolism [49]. Thus, leptin has an important role in helping FM to remain relatively constant during adulthood. There is a gender difference in leptin levels which develops at puberty and is believed to be induced by sex hormones.

Leptin concentrations are higher per kilogram body weight in women than men. This difference is eliminated after adjusting for circulating concentrations of sex hormones [50]. Studies have found that leptin production was inhibited by androgens and promoted by oestrogens $[26,50]$. Oestrogen has direct effects on FM as it upregulates leptin expression in adipocytes [51]. Central effects may also be 
present as oestrogen receptors have been detected in the hypothalamic nuclei controlling energy homeostasis. Circulating oestrogens are proposed to bind to these receptors and alter hypothalamic sensitivity to leptin-mediated signals, thus influencing secretion of leptin and possibly influencing metabolism and even fertility [52-54].

However, the relationship between leptin, oestrogen, and body composition is complex, as there is no change in leptin with menopause or with oestrogen replacement therapy [26]. Weight loss is associated with reduced leptin levels and hypogonadism [55]. In addition, the hyperandrogenism and diminished oestrogen surge in polycystic ovaries disease do not affect leptin levels [56, 57]. Therefore, the role of leptin in regulating FM is potentially influenced by oestrogen however, the mechanism of action is not completely clear.

\section{Energy Balance in Pregnancy}

Female reproduction requires increased amounts of energy. Yet, throughout history, women have carried their conceptus to term under a wide range of nutritional conditions. This suggests the presence of powerful metabolic adaptations [3]. During gestation, energy is required to grow the tissues of conception and reproduction, to maintain these tissues, and to prepare for lactation. Butte and King [58] found that an average weight gain of $13.8 \mathrm{~kg}$, which includes $4.3 \mathrm{~kg}$ of fat, represents gestational energy needs. Based on this model, the Food and Agriculture Organization, World Health Organization, and United Nations University have calculated the energy requirement of pregnancy to be 360 $370 \mathrm{MJ}$. This equates to an extra $1300 \mathrm{~kJ} /$ day, which is $15 \%$ above non-pregnant needs. However, gestational requirements have been shown to range from $30 \mathrm{MJ}$ to $520 \mathrm{MJ}$ in undernourished to overnourished women [59]. This variability points to the presence of metabolic adaptations for sustaining pregnancy under different nutritional conditions.

In theory, this additional demand can be met by either increasing energy intake, decreasing expenditure, and/or mobilising fat stores. In contrast to expectations, numerous prospective and cross-sectional studies found that the first half of pregnancy is associated with little or no increase in energy intake [6, 60-62]. One study followed women prospectively through pregnancy and reported that energy intake in the first trimester of pregnancy is identical to pre-pregnancy [63]. Instead of reducing energy expenditure increased progressively during gestation $[4,64,65]$. Similarly, changes in diet-induced thermogenesis during pregnancy have not been consistently reported and therefore a reduction in diet-induced thermogenesis may not account for the positive energy balance $[4,33,66-70]$.

These above observations raise the possibility that the energy costs of pregnancy are met by reductions in total energy expenditure. However, conclusive evidence fails to show that significant increases in energy intake or decreases in energy expenditure are the major contributors to the increase in FM in the first half of pregnancy. It is also important to note that pregnancy is a very plastic metabolic state, because even undernourished women can maintain
FM [59]. Therefore, the cause of gestational fat gain may be mainly due to changes in metabolic pathways regulating the oxidation or storage of specific fuels especially fat.

\section{Conclusion}

Throughout their reproductive life, women maintain a higher proportion of body fat compared to men, and this difference is accentuated during the hyperoestrogenic state of pregnancy. However, studies have failed to demonstrate an energy surplus on all accounts. It is possible that women underestimate their food intake; however, some studies have reported that men underestimate their food intake compared with women [71]. The differences in physical activity between the sexes also need to be considered. Women do have a greater percent body fat, and it is possible that ovarian hormones, particularly oestrogen, may account for these observations by promoting postprandial conversion of dietary energy into fat. This theory needs to be supported by larger prospective studies and studies during natural hyperoestrogenic states such as pregnancy. Oestrogens' actions may be mediated through hepatocyte and adipocyte targets and through regulation of hormones such as leptin. Further studies are needed to elucidate how these hormonal pathways interact and influence their targets.

When considering lifestyle modifications, the sex difference in energy metabolism needs to be considered. Goals that take into account gender rather than just body weight or energy intake need to be utilised. Considering the high prevalence of obesity in modern society, it is important to understand the factors that regulate energy homeostasis and subsequently contribute to excess body fat. In the future, this understanding may culminate in strategies to control or reverse fat gain that do not only emphasise energy restriction.

\section{References}

[1] A. K. Kant and B. I. Graubard, "Secular trends in patterns of self-reported food consumption of adult Americans: NHANES 1971-1975 to NHANES 1999-2002," American Journal of Clinical Nutrition, vol. 84, no. 5, pp. 1215-1223, 2006.

[2] M. A. Tarnopolsky, "Sex differences in exercise metabolism and the role of 17-beta estradiol," Medicine and Science in Sports and Exercise, vol. 40, no. 4, pp. 648-654, 2008.

[3] A. J. O'Sullivan, "Does oestrogen allow women to store fat more efficiently? A biological advantage for fertility and gestation," Obesity Reviews, vol. 10, no. 2, pp. 168-177, 2009.

[4] L. E. Kopp-Hoolihan, M. D. Van Loan, W. W. Wong, and J. C. King, "Longitudinal assessment of energy balance in wellnourished, pregnant women," American Journal of Clinical Nutrition, vol. 69, no. 4, pp. 697-704, 1999.

[5] FAO/WHO/UNU Expert Consultation, "Human energy requirements," Food and Nutrition Technical Report, FAO, Rome, Italy, 2004.

[6] J. V. Durnin, F. M. McKillop, S. Grant, and G. Fitzgerald, "Is nutritional status endangered by virtually no extra intake during pregnancy," Lancet, vol. 2, no. 8459, pp. 823-825, 1985. 
[7] J. M. Van Raaij, S. H. Vermaat-Miedema, C. M. Schonk, M. E. Peek, and J. G. Hautvast, "Energy requirements of pregnancy in The Netherlands," Lancet, vol. 2, no. 8565, pp. 953-955, 1987.

[8] J. S. Mayes, J. P. McCann, T. C. Ownbey, and G. H. Watson, "Regional differences and up-regulation of progesterone receptors in adipose tissues from oestrogen-treated sheep," Journal of Endocrinology, vol. 148, no. 1, pp. 19-25, 1996.

[9] I. Weinstein, C. Soler-Argilaga, H. V. Werner, and M. Heimberg, "Effects of ethynyloestradiol on the metabolism of [114C] oleate by perfused livers and hepatocytes from female rats," Biochemical Journal, vol. 180, no. 2, pp. 265-271, 1979.

[10] W. C. Chumlea, S. S. Gio, R. J. Kuczmarski et al., "Body composition estimates from NHANES III bioelectrical impedance data," International Journal of Obesity, vol. 26, no. 12, pp. 1596-1609, 2002.

[11] J. C. K. Wells, "Sexual dimorphism of body composition," Best Practice and Research Clinical Endocrinology and Metabolism, vol. 21, no. 3, pp. 415-430, 2007.

[12] A. Pietrobelli, D. B. Allison, S. Heshka et al., "Sexual dimorphism in the energy content of weight change," International Journal of Obesity, vol. 26, no. 10, pp. 1339-1348, 2002.

[13] T. A. Hagobian, C. G. Sharoff, B. R. Stephens et al., "Effects of exercise on energy-regulating hormones and appetite in men and women," American Journal of Physiology, vol. 296, no. 2, pp. R233-R242, 2009.

[14] R. N. Cortright, M. P. Chandler, P. W. Lemon, and S. E. Dicarlo, "Daily exercise reduces fat, protein and body mass in male but not female rats," Physiology and Behavior, vol. 62, no. 1, pp. 105-111, 1997.

[15] R. N. Cortright and T. R. Koves, "Sex differences in substrate metabolism and energy homeostasis," Canadian Journal of Applied Physiology, vol. 25, no. 4, pp. 288-311, 2000.

[16] K. B. Hoyenga and K. T. Hoyenga, "Gender and energy balance: sex differences in adaptations for feast and famine," Physiology and Behavior, vol. 28, no. 3, pp. 545-563, 1982.

[17] B. J. Rolls and E. A. Rowe, "Exercise and the development and persistence of dietary obesity in male and female rats," Physiology and Behavior, vol. 23, no. 2, pp. 241-247, 1979.

[18] J. E. Donnelly and B. K. Smith, "Is exercise effective for weight loss with ad libitum diet? Energy balance, compensation, and gender differences," Exercise and Sport Sciences Reviews, vol. 33, no. 4, pp. 169-174, 2005.

[19] J. W. Anderson, L. Grant, L. Gotthelf, and L. T. Stifler, "Weight loss and long-term follow-up of severely obese individuals treated with an intense behavioral program," International Journal of Obesity, vol. 31, no. 3, pp. 488-493, 2007.

[20] S. J. Fomon, F. Haschke, E. E. Ziegler, and S. E. Nelson, "Body composition of reference children from birth to age 10 years," American Journal of Clinical Nutrition, vol. 35, no. 5, supplement, pp. 1169-1175, 1982.

[21] G. C. Henderson, J. A. Fattor, M. A. Horning et al., "Lipolysis and fatty acid metabolism in men and women during the postexercise recovery period," Journal of Physiology, vol. 584, no. 3, pp. 963-981, 2007.

[22] E. Blaak, "Gender differences in fat metabolism," Current Opinion in Clinical Nutrition and Metabolic Care, vol. 4, no. 6, pp. 499-502, 2001.

[23] M. D. Jensen, "Gender differences in regional fatty acid metabolism before and after meal ingestion," Journal of Clinical Investigation, vol. 96, no. 5, pp. 2297-2303, 1995.
[24] A. P. Uranga, J. Levine, and M. Jensen, "Isotope tracer measures of meal fatty acid metabolism: reproducibility and effects of the menstrual cycle," American Journal of Physiology, vol. 288, no. 3, pp. E547-E555, 2005.

[25] S. Santosa and M. D. Jensen, "Why are we shaped differently, and why does it matter?" American Journal of Physiology, vol. 295, no. 3, pp. E531-E535, 2008.

[26] J. S. Mayes and G. H. Watson, "Direct effects of sex steroid hormones on adipose tissues and obesity," Obesity Reviews, vol. 5, no. 4, pp. 197-216, 2004.

[27] R. Lwin, B. Darnell, R. Oster et al., "Effect of oral estrogen on substrate utilization in postmenopausal women," Fertility and Sterility, vol. 90, no. 4, pp. 1275-1278, 2008.

[28] J. Gibney, G. Johannsson, K. C. Leung, and K. K. Y. Ho, "Comparison of the metabolic effects of raloxifene and oral estrogen in postmenopausal and growth hormone-deficient women," Journal of Clinical Endocrinology and Metabolism, vol. 90, no. 7, pp. 3897-3903, 2005.

[29] A. J. O'Sullivan, L. J. Crampton, J. Freund, and K. K. Y. Ho, "The route of estrogen replacement therapy confers divergent effects on substrate oxidation and body composition in postmenopausal women," Journal of Clinical Investigation, vol. 102, no. 5, pp. 1035-1040, 1998.

[30] H. J. C. Bennink, "Are all estrogens the same?" Maturitas, vol. 47, no. 4, pp. 269-275, 2004.

[31] J. P. Raynaud, M. M. Bouton, and D. Gallet-Bourquin, "Comparative study of estrogen action," Molecular Pharmacology, vol. 9, no. 4, pp. 520-533, 1973.

[32] C. J. K. Spaaij, J. M. A. van Raaij, L. J. M. van der Heijden et al., "No substantial reduction of the thermic effect of a meal during pregnancy in well-nourished Dutch women," British Journal of Nutrition, vol. 71, no. 3, pp. 335-344, 1994.

[33] L. E. Nagy and J. C. King, "Postprandial energy expenditure and respiratory quotient during early and late pregnancy," American Journal of Clinical Nutrition, vol. 40, no. 6, pp. 12581263, 1984.

[34] A. J. O’Sullivan, A. Martin, and M. A. Brown, "Efficient fat storage in premenopausal women and in early pregnancy: a role for estrogen," Journal of Clinical Endocrinology and Metabolism, vol. 86, no. 10, pp. 4951-4956, 2001.

[35] R. K. Ockner, N. Lysenko, J. A. Manning, S. E. Monroe, and D. A. Burnett, "Sex steroid modulation of fatty acid utilization and fatty acid binding protein concentration in rat liver," Journal of Clinical Investigation, vol. 65, no. 5, pp. 1013-1023, 1980.

[36] J. M. Potter and P. J. Nestel, “The hyperlipidemia of pregnancy in normal and complicated pregnancies," American Journal of Obstetrics and Gynecology, vol. 133, no. 2, pp. 165-170, 1979.

[37] B. W. Walsh, I. Schiff, B. Rosner, L. Greenberg, V. Ravnikar, and F. M. Sacks, "Effects of postmenopausal estrogen replacement on the concentrations and metabolism of plasma lipoproteins," New England Journal of Medicine, vol. 325, no. 17, pp. 1196-1204, 1991.

[38] A. J. O'Sullivan, D. M. Hoffman, and K. K. Y. Ho, "Estrogen, lipid oxidation, and body fat," New England Journal of Medicine, vol. 333, no. 10, pp. 669-670, 1995.

[39] T. J. Horton, E. K. Miller, D. Glueck, and K. Tench, "No effect of menstrual cycle phase on glucose kinetics and fuel oxidation during moderate-intensity exercise," American Journal of Physiology, vol. 282, no. 4, pp. E752-E762, 2002.

[40] P. Bjorntorp, "Hormonal control of regional fat distribution," Human Reproduction, vol. 12, supplement, pp. 21-25, 1997.

[41] S. B. Pedersen, P. S. Hansen, S. Lund, P. H. Andersen, A. Odgaard, and B. Richelsen, "Identification of oestrogen receptors and oestrogen receptor mRNA in human adipose 
tissue," European Journal of Clinical Investigation, vol. 26, no. 4, pp. 262-269, 1996.

[42] J. D. Wilson and D.W. Foster, Eds., William's Textbook of Endocrinology, Saunders, Philadelphia, Pa, USA, 8th edition, 1992.

[43] J. M. Elbers, H. Asscheman, J. C. Seidell, J. A. J. Megens, and L. J. Gooren, "Long-term testosterone administration increases visceral fat in female to male transsexuals," Journal of Clinical Endocrinology and Metabolism, vol. 82, no. 7, pp. 2044-2047, 1997.

[44] V. Vicennati, A. Gambineri, F. Calzoni et al., "Serum leptin in obese women with polycystic ovary syndrome is correlated with body weight and fat distribution but not with androgen and insulin levels," Metabolism, vol. 47, no. 8, pp. 988-992, 1998.

[45] J. C. Lovejoy, J. A. Bray, M. O. Bourgeois et al., "Exogenous androgens influence body composition and regional body fat distribution in obese postmenopausal women-a clinical research center study," Journal of Clinical Endocrinology and Metabolism, vol. 81, no. 6, pp. 2198-2203, 1996.

[46] S. Lemieux, J. P. Despres, S. Moorjani et al., "Are gender differences in cardiovascular disease risk factors explained by the level of visceral adipose tissue?" Diabetologia, vol. 37, no. 8, pp. 757-764, 1994.

[47] K. Kotani, K. Tokunaga, S. Fujioka et al., "Sexual dimorphism of age-related changes in whole-body fat distribution in the obese," International Journal of Obesity, vol. 18, no. 4, pp. 207212, 1994.

[48] R. J. Troisi, A. M. Wolf, J. E. Mason et al., "Relation of body fat distribution to reproductive factors in pre- and postmenopausal women," Obesity Research, vol. 3, no. 2, pp. 143-151, 1995.

[49] G. Frühbeck, S. A. Jebb, and A. M. Prentice, "Leptin: physiology and pathophysiology," Clinical Physiology, vol. 18, no. 5, pp. 399-419, 1998.

[50] M. Rosenbaum and R. L. Leibel, "Role of gonadal steroids in the sexual dimorphisms in body composition and circulating concentrations of leptin," Journal of Clinical Endocrinology and Metabolism, vol. 84, no. 6, pp. 1784-1789, 1999.

[51] F. Machinal-Quélin, M. N. Dieudonné, R. Pecquery, M. C. Leneveu, and Y. Giudicelli, "Direct in vitro effects of androgens and estrogens on ob gene expression and leptin secretion in human adipose tissue," Endocrine, vol. 18, no. 2, pp. 179-184, 2002.

[52] B. Gréco, D. A. Edwards, D. Zumpe, and A. N. Clancy, "Androgen receptor and mating-induced Fos immunoreactivity are co-localized in limbic and midbrain neurons that project to the male rat medial preoptic area," Brain Research, vol. 781, no. 1-2, pp. 15-24, 1998.

[53] M. J. Kelly and J. Qiu, "Estrogen signaling in hypothalamic circuits controlling reproduction," Brain Research, vol. 1364, pp. 44-52, 2010.

[54] B. D. Bianco-Borges, F. J. Cabral, and C. R. Franci, "Coexpression of leptin and oestrogen receptors in the preoptichypothalamic area," Journal of Neuroendocrinology, vol. 22, no. 9, pp. 996-1003, 2010.

[55] J. L. Chan and C. S. Mantzoros, "Role of leptin in energydeprivation states: normal human physiology and clinical implications for hypothalamic amenorrhoea and anorexia nervosa," Lancet, vol. 366, no. 9479, pp. 74-85, 2005.

[56] G. A. Laughlin, A. J. Morales, and S. S. C. Yen, "Serum leptin levels in women with polycystic ovary syndrome: the role of insulin resistance/hyperinsulinemia," Journal of Clinical
Endocrinology and Metabolism, vol. 82, no. 6, pp. 1692-1696, 1997.

[57] J. Rouru, L. Anttila, P. Koskinen et al., "Serum leptin concentrations in women with polycystic ovary syndrome," Journal of Clinical Endocrinology and Metabolism, vol. 82, no. 6, pp. 1697-1700, 1997.

[58] N. F. Butte and J. C. King, "Energy requirements during pregnancy and lactation," Public Health Nutrition, vol. 8, no. 7a, pp. 1010-1027, 2005.

[59] A. M. Prentice and G. R. Goldberg, "Energy adaptations in human pregnancy: limits and long-term consequences," American Journal of Clinical Nutrition, vol. 71, no. 5, supplement, pp. 1226S-1232S, 2000.

[60] N. T. Rad, C. Ritterath, and T. Siegmud et al., "Longitudinal analysis of changes in energy intake and macronutrient composition during pregnancy and 6 weeks post-partum," Archives of Gynecology and Obstetrics, vol. 283, no. 2, pp. 185190, 2011.

[61] M. W. Blackburn and D. H. Calloway, "Energy expenditure and consumption of mature, pregnant and lactating women," Journal of the American Dietetic Association, vol. 69, no. 1, pp. 29-37, 1976.

[62] R. M. English and N. E. Hitchcock, "Nutrient intakes during pregnancy, lactation and after the cessation of lactation in a group of Australian women," British Journal of Nutrition, vol. 22, no. 4, pp. 615-624, 1968.

[63] J. M. van Raaij, S. H. Vermaat-Miedema, C. M. Schonk, M. E. Peek, and J. G. Hautvast, "Energy requirements of pregnancy in The Netherlands," Lancet, vol. 2, no. 8565, pp. 953-955, 1987.

[64] N. F. Butte, W. W. Wong, M. S. Treuth, K. J. Ellis, and S. E. O’Brian, "Energy requirements during pregnancy based on total energy expenditure and energy deposition," American Journal of Clinical Nutrition, vol. 79, no. 6, pp. 1078-1087, 2004.

[65] M. Lof and E. Forsum, "Activity pattern and energy expenditure due to physical activity before and during pregnancey in healthy Swedish women," British Journal of Nutrition, vol. 95, no. 2, pp. 296-302, 2006.

[66] M. N. Bronstein, R. P. Mak, and J. C. King, "The thermic effect of food in normal-weight and overweight pregnant women," British Journal of Nutrition, vol. 74, no. 2, pp. 261-275, 1995.

[67] L. S. Piers, S. N. Diggavi, S. Thangam, J. M. van Raaij, P. S. Shetty, and J. G. Hautvast, "Changes in energy expenditure, anthropometry, and energy intake during the course of pregnancy and lactation in well-nourished Indian women," American Journal of Clinical Nutrition, vol. 61, no. 3, pp. 501513, 1995.

[68] P. J. Illingworth, R. T. Jung, P. W. Howie, and T. E. Isles, "Reduction in postprandial energy expenditure during pregnancy," British Medical Journal, vol. 294, no. 6587, pp. 15731576, 1987.

[69] A. M. Prentice, G. R. Goldberg, H. L. Davies, P. R. Murgatroyd, and W. Scott, "Energy-sparing adaptations in human pregnancy assessed by whole-body calorimetry," British Journal of Nutrition, vol. 62, no. 1, pp. 5-22, 1989.

[70] C. J. Spaaij, J. M. A. van Raaij, L. C. de Groot et al., "No substantial reduction of the thermic effect of a meal during pregnancy in well-nourished Dutch women," British Journal of Nutrition, vol. 71, no. 3, pp. 335-344, 1994.

[71] D. Bedard, B. Shatenstein, and S. Nadon, "Underreporting of energy intake from a self-administered food-frequency questionnaire completed by adults in Montreal," Public Health Nutrition, vol. 7, no. 5, pp. 675-681, 2004. 


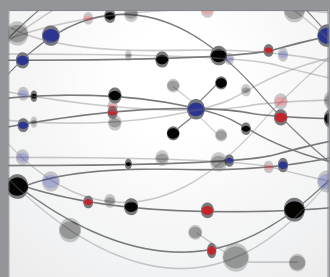

The Scientific World Journal
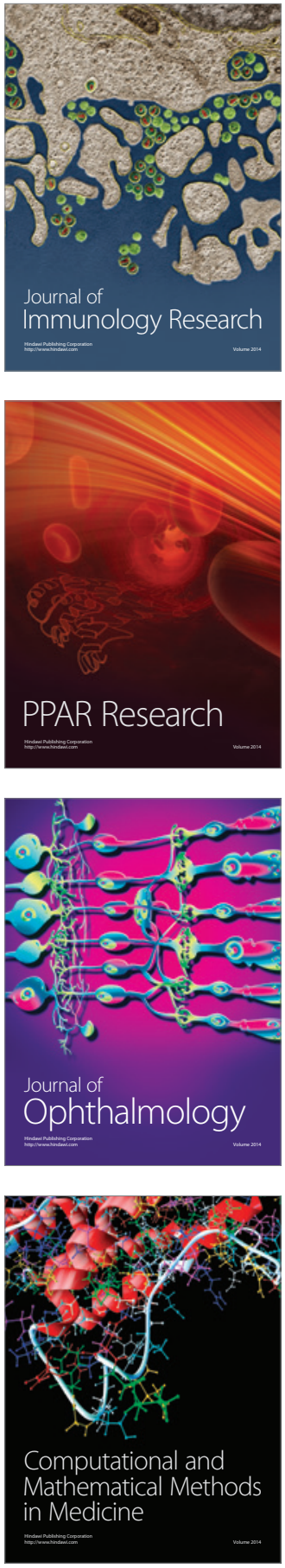

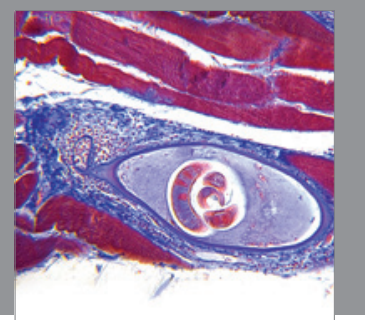

Gastroenterology

Research and Practice
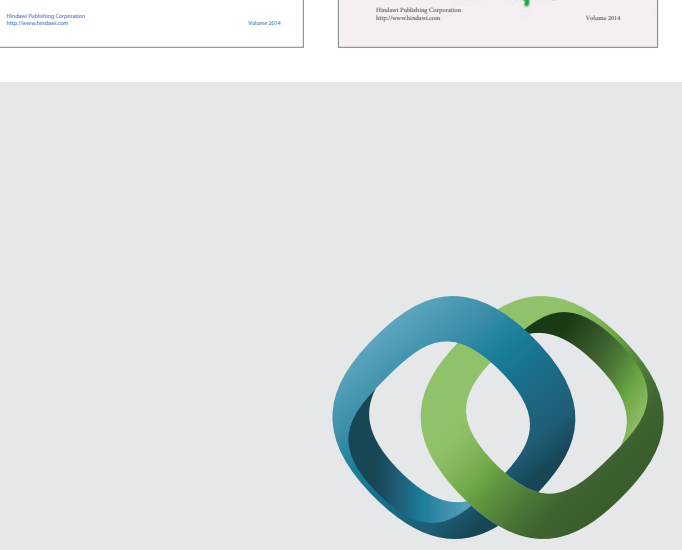

\section{Hindawi}

Submit your manuscripts at

http://www.hindawi.com
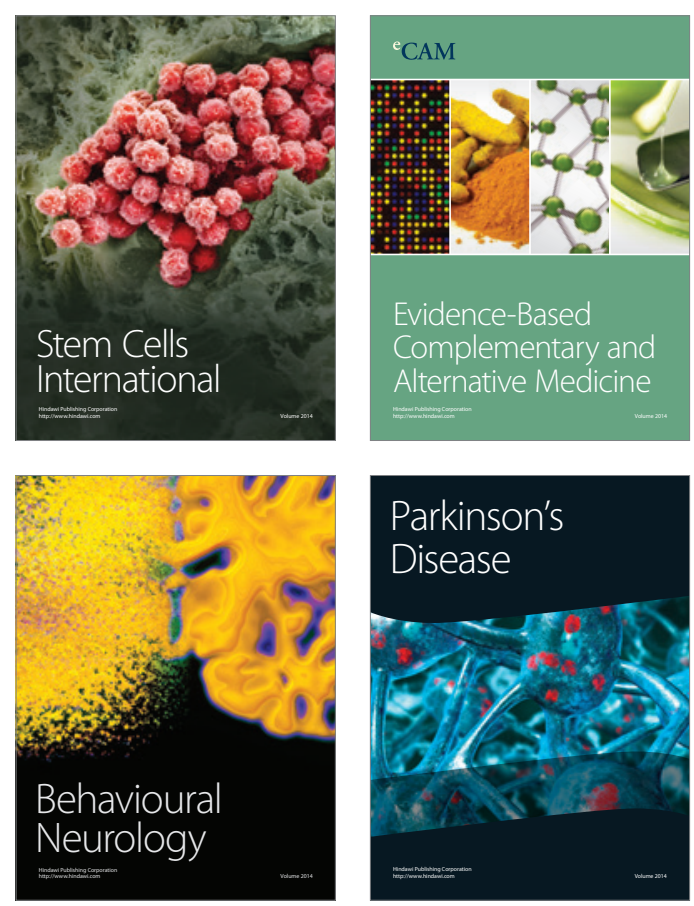

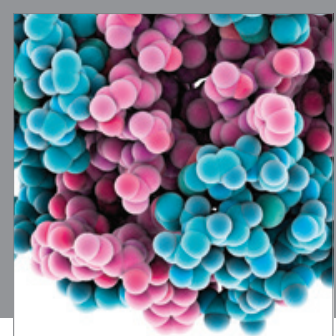

Journal of
Diabetes Research

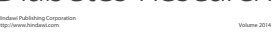

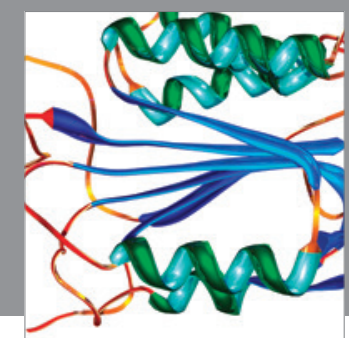

Disease Markers
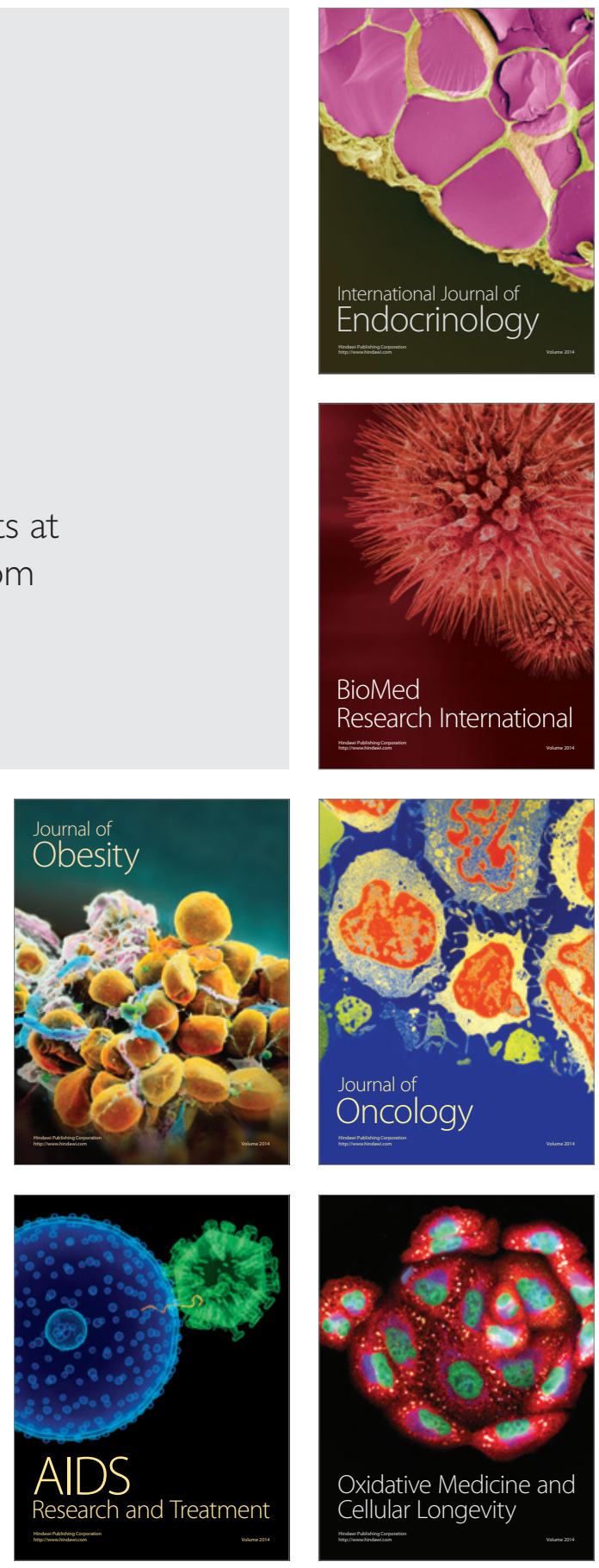